\title{
Three-phase Three-level (NPC) Shunt Active Power Filter Performances based on PWM and ANN's Controllers for Harmonic Current Compensation
}

\author{
Chennai Salim ${ }^{1}$ and Benchouia Mohamed Toufik ${ }^{2}$ \\ ${ }^{1}$ Electrical Engineering Department, Birine Nuclear Research Center, Algeria, \\ ${ }^{2}$ Laboratory L.G.E.B., Biskra University, Algeria \\ chenaisalimov@yahoo.fr
}

\begin{abstract}
This paper presents a shunt active power filter performances based on threelevel (NPC) inverter using conventional pulse width modulation (PWM) and Ann's controllers to mitigate current harmonics generated by non-linear loads. Shunt APF is the best solution to eliminate harmonics drawn from nonlinear load especially for low power system, the conventional scheme based on the two level inverter controlled by hysteresis controller presents several drawbacks such us high inverse voltage applied to power components, degraded output voltage inverter waveforms, etc. Today three-level (NPC) inverter and intelligent controllers are widely used in different industrial applications. To take advantages of these inverter topology and artificial intelligent controller performance a novel control scheme based on Ann's current controller is proposed in this work. The control strategy adopted is the synchronous current detection method, it is easy to implement and permits a good extraction of reference currents compensation. The numerical simulation is performed using MATLAB-Simulink and SimPowerSystem Toolbox. The simulation results obtained in steady and transit states show the effectiveness and the superiority of Ann systems compared to PWM controller.
\end{abstract}

Keywords: Shunt active power filter, intelligent controller, Ann's, Three-level (NPC) inverter, Harmonic currents compensation, power quality improvement.

\section{Introduction}

With the proliferation of nonlinear power electronics loads, the problem of harmonic is severity, which influences the quality of power grid. Harmonic currents produced by nonlinear loads, such as rectifiers, power electronics converters, controllers for adjustable-speed motor drives, electronic power supplies, DC motor drives, battery chargers, electronic ballasts are responsible for the rise in PQ related problems [1]. Passive power filter is a traditional harmonic restraint method, this solution have been used to eliminate current harmonics and to increase the power factor, which are simple and low cost. However, the use of passive filter has many disadvantages, such as large size, series or parallel resonance with the system impedance. [2]. One of the most popular active filters is the Shunt Active Power Filter; Shunt APF have been researched and developed, that they have gradually been recognized as a feasible solution to the problems created by non-linear loads. Active filter is used, these last years, to improve power quality on the load side from the grid by injecting compensating currents.

The performance of any active filter mainly depends on the reference current generation strategy, hysteresis or pulse width modulation signals, topology of the power converter, etc... Instantaneous power theory [3] and synchronous reference frame detection method [4] are widely used in different research work, these techniques provide good results under different voltage source conditions but present some drawbacks such us a much calculations number, necessitate complex mathematical transformation and difficult implementation in practice [5]. Synchronous current detection method is another interesting method; it is concise and requires less computational calculation compared the two other methods. In this work, this technique is adopted to use with three-level (NPC) inverter after several modifications.

Received: April 28 ${ }^{\text {th }}, 2013$. Accepted: March 14 ${ }^{\text {th }}, 2014$ 
In other side, three-level inverter is one of the most multilevel converters used successfully in medium and high power applications [6], [7]. Their advantages are well known as very low harmonic distortion, smaller common-mode (C-M) portions, and lower switching frequency and power loss. However, the control of a three-level inverter is more complex than that of a two-level inverter because of large numbers of inverter switching states.

The controller is the main part of any active power filter operation and has been a subject of many researches in recent years. Among the various current control techniques, hysteresis current control is the most extensively used technique. It is easy to realize with high accuracy and fast response. In the hysteresis control technique the error function is centred in a preset hysteresis band. When the error exceeds the upper or lower hysteresis limit the hysteretic controller makes an appropriate switching decision to control the error within the preset band. However, variable switching frequency and high ripple content are the main disadvantages of hysteresis current control [8]. To improve the control performances there's a great tendency to use intelligent control techniques, particularly fuzzy logic or artificial neural network controllers [9], [10]. Their principal advantages are robustness, ability to control nonlinear systems, no need accurate mathematical model, etc.

This paper presents the performance of the three-level (NPC) shunt active filter based on PWM and Ann's controllers. The model and numerical simulation in transient and steady states conditions are developed and performed using Matlab-Simulink and SimPowerSystem Toolbox.

\section{Shunt active power filter}

The basic block diagram including non linear load compensation principle of a shunt active power filters based on three-level (NPC) inverter is shown in Figure 1. It is controlled to draw/supply a compensated current from/to the utility, such that it cancels harmonic currents of the non-linear load and makes the source current in phase with the different waveforms. The current drawn from the power system at the coupling point of the shunt APF will result sinusoidal [11], [12].

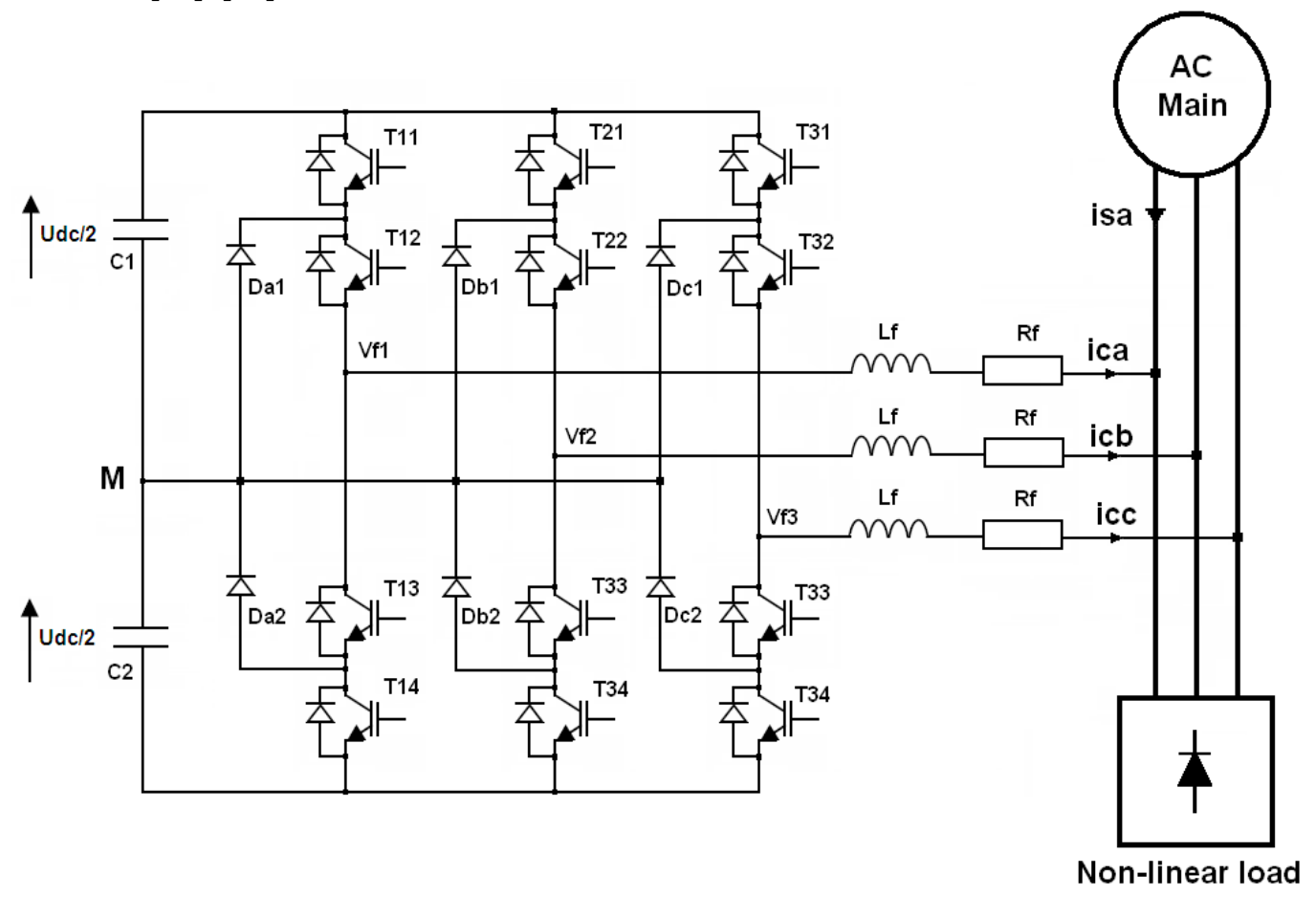

Figure 1. Three-level (NPC) Shunt active filter 


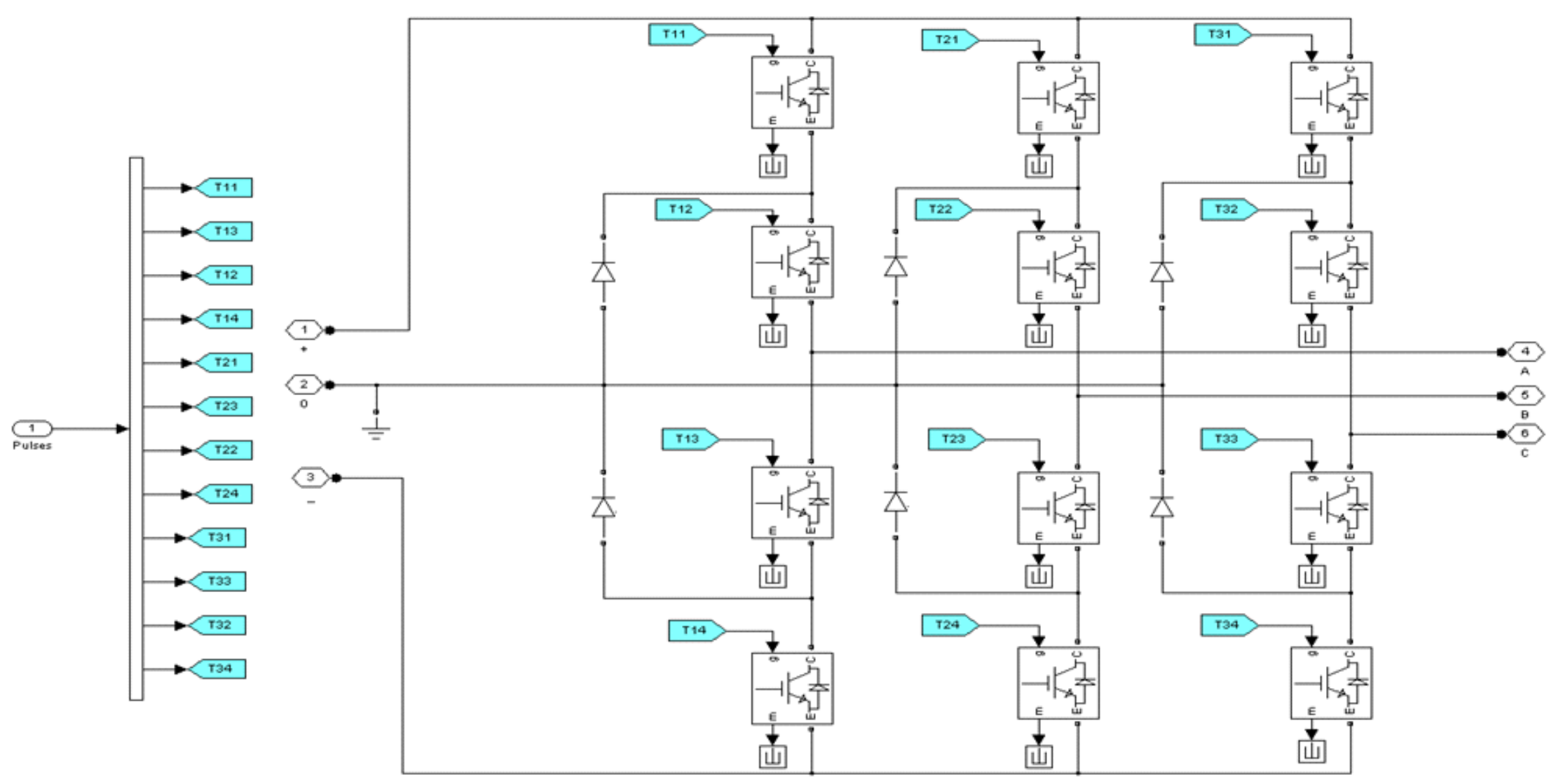

Figure 2. Circuit topology of three-level (NPC) inverter 
Table 1. Switching states of three-level (NPC) inverter

\begin{tabular}{|c|c|c|c|c|c|}
\hline Switching states & Voltage output & T11 & T12 & T13 & T14 \\
\hline A & Udc/2 & ON & ON & OFF & OFF \\
\hline $\mathbf{0}$ & 0 & OFF & ON & ON & OFF \\
\hline B & $-U d c / 2$ & OFF & OFF & ON & ON \\
\hline
\end{tabular}

\section{Control strategies}

The strategy control used is the synchronous reference current detection method is shown in Figure 2. It's concise and requires less computational efforts than many others method control [12], [13]. The compensating currents of active filter are calculated by sensing the load currents, the current delivered by DC voltage regulator $\mathrm{I}^{*} \mathrm{smd}$, peak voltage of AC source (Vsm) and zero crossing point of source voltage.

$$
\begin{aligned}
& v s a(t)=V s m \cdot \sin (\omega t) \\
& v s b(t)=V s m \cdot \sin \left(\omega t-2 \frac{\pi}{3}\right) \\
& v s c(t)=V s m \cdot \sin \left(\omega t-4 \frac{\pi}{3}\right)
\end{aligned}
$$

In order to compensate the current harmonics, the average active power of AC source must be equal with PLav, considering the unity power factor of AC source side currents the average active power of AC source can be:

$$
P_{s}=\frac{3}{2} V_{s m} \cdot I_{s m p}^{*}=P_{L a v}
$$

From this equation, the first component of AC side current can be calculated:

$$
I_{s m p}^{*}=\frac{2}{3} \frac{P_{L a v}}{V_{s m}}
$$

The second component of AC source current I*smd is obtained from DC capacitor voltage regulator. The desired peak current of $\mathrm{AC}$ source can be calculated as bellow:

$$
I_{s m}^{*}=I_{s m p}^{*}+I_{s m d}^{*}
$$

The AC source currents must be sinusoidal and in phase with source voltages, theses currents can be calculated with multiplying peak source current to a unity sinusoidal signal, these unity signals can be obtained from equation (5):

$$
\begin{aligned}
& i_{u a}(t)=\frac{v_{s a}}{V_{s m}} \\
& i_{u b}(t)=\frac{v_{s b}}{V_{s m}} \\
& i_{u c}(t)=\frac{v_{s c}}{V_{s m}}
\end{aligned}
$$




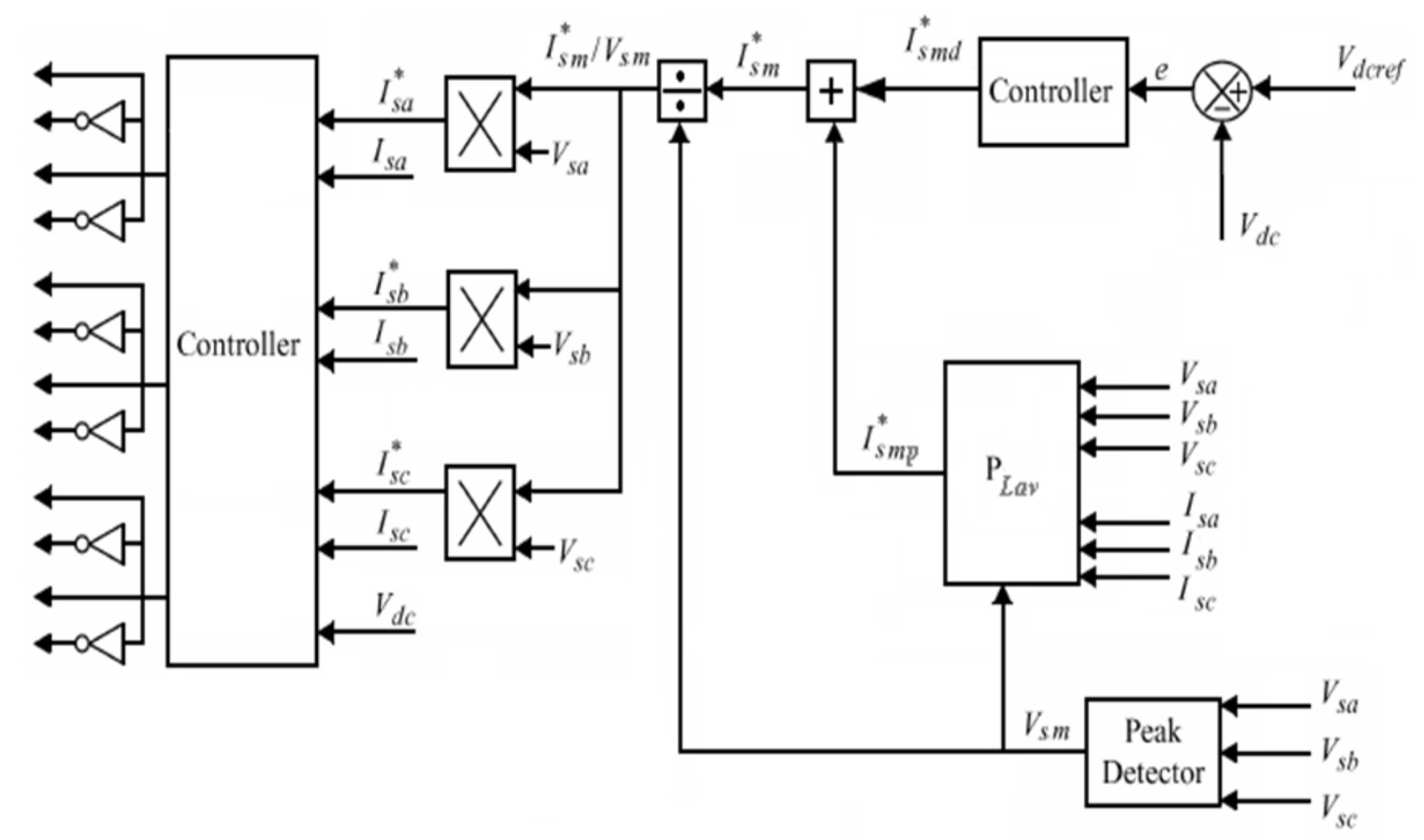

Figure 3. Synchronous current detection method control 
The desired source side currents can be obtained from equation (6):

$$
\begin{aligned}
& i_{s a}^{*}(t)=I_{s m}^{*} \cdot i_{u a} \\
& i_{s b}^{*}(t)=I_{s m}^{*} \cdot i_{u b} \\
& i_{s c}^{*}(t)=I_{s m}^{*} \cdot i_{u c}
\end{aligned}
$$

Finally, the reference currents can be obtained from (7):

$$
\begin{aligned}
& i_{c a}^{*}(t)=i_{s a}^{*}(t)-i_{L a}^{*}(t) \\
& i_{c b}^{*}(t)=i_{s b}^{*}(t)-i_{L b}^{*}(t) \\
& i_{c c}^{*}(t)=i_{s c}^{*}(t)-i_{L c}^{*}(t)
\end{aligned}
$$

To compensate the inverter losses and regulate the DC link voltage Udc, a proportional integral voltage controller is used. The control loop consists of the comparison of the measured voltage $(\mathrm{Udc}=\mathrm{Udc} 1+\mathrm{Udc} 2)$ with the reference voltage $\mathrm{Udc}-\mathrm{ref}$ and $\Delta \mathrm{Udc}=\mathrm{Udc}-\mathrm{ref}-\mathrm{Udc}$. The loop generates corresponding current $\mathrm{I}^{*}$ smd as given by:

$$
I_{s m d}^{*}=K_{p} \cdot \Delta U_{d c}+K_{i} \int \Delta U_{d c} d t
$$

\section{Shunt APF Control}

\section{A. PWM current controller}

The main component of any active filter is the controller; the conventional scheme is based on hysteresis controller, it is very complicated and requires many calculations for its implementation [15]. To replace the conventional hysteresis control scheme a novel logic controller to use with three-level (NPC) inverter given by Figure (4) is proposed. The difference between the injected current and the reference current determines the reference signal (e). This signal is compared with two triangular-carrying identical waves shifted from one to the other by a half-period of chopping and generating the switching pulses. The control of inverter is summarized in the two following stages:

Determination of the intermediate signals Vi1 and Vi2:

- If error Ec $\geq$ carrying 1 Then Vil $=1$,

- If error Ec $<$ carrying 1 Then Vil $=0$,

- If error Ec $\geq$ carrying 2 Then $\mathrm{Vi} 2=0$,

- If error Ec < carrying 2 Then Vi2=-1.

Determination of control signals of the switches Tij $(\mathrm{i}=1,2,3 ; \mathrm{j}=1,2,3,4)$ :

- If $(\mathrm{Vi} 1+\mathrm{Vi} 2)=1$ Then $\mathrm{Ti} 1=1, \mathrm{Ti} 2=1, \mathrm{Ti} 3=0, \mathrm{Ti} 4=0$,

- If $(\mathrm{Vi} 1+\mathrm{Vi} 2)=0$ Then Ti1 $=0, \mathrm{Ti} 2=1, \mathrm{Ti} 3=1, \mathrm{Ti} 4=0$,

- If $(\mathrm{Vi1}+\mathrm{Vi} 2)=-1$ Then Ti1 $=0, \mathrm{Ti} 2=0, \mathrm{Ti} 3=1, \mathrm{Ti} 4=1$.

The bloc diagram of the three-level (NPC) shunt active power filter based on conventional current controller is shown in Figure (5). 


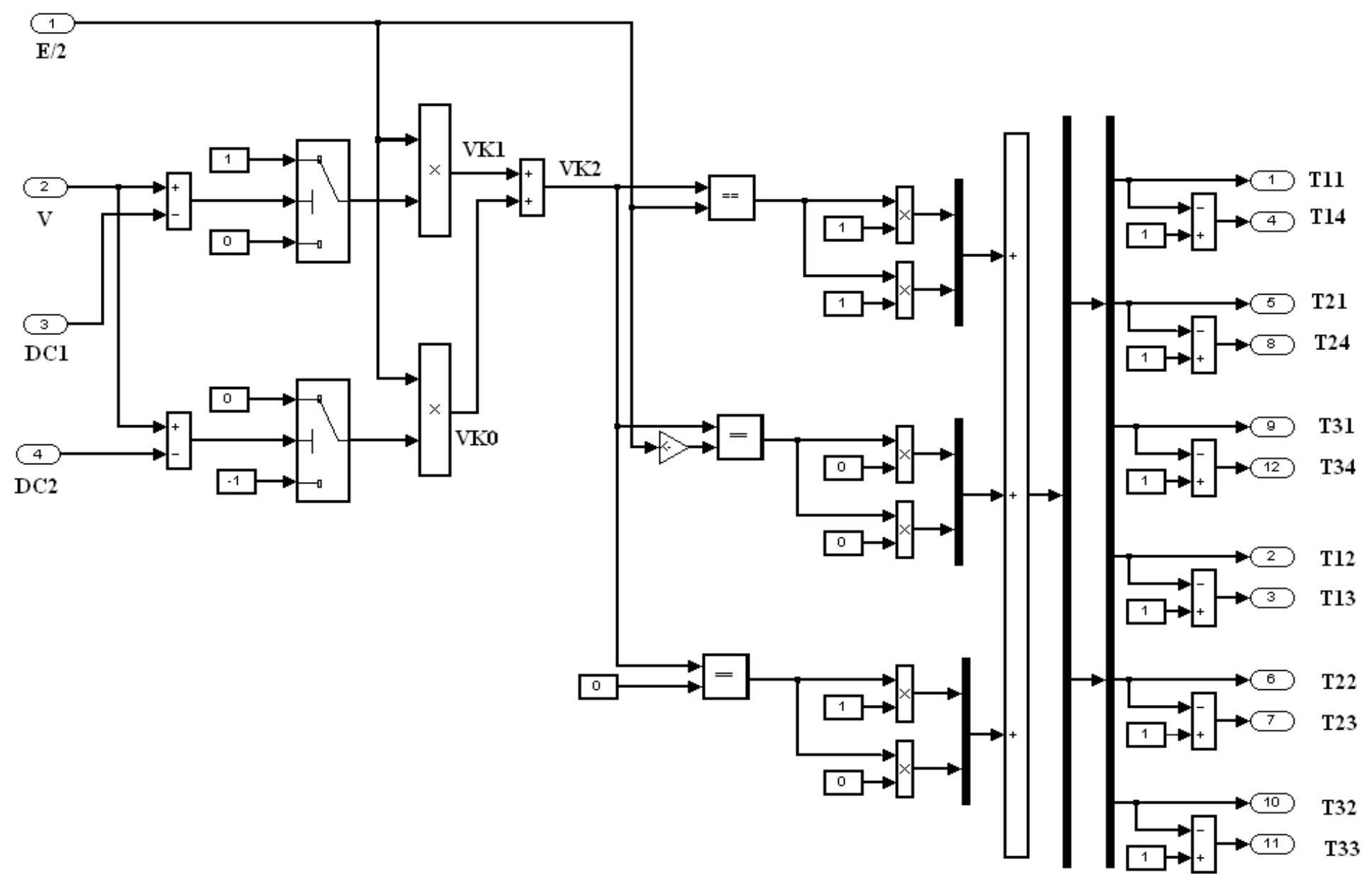

Figure 4. Three-level (NPC) inverter PWM logic control 


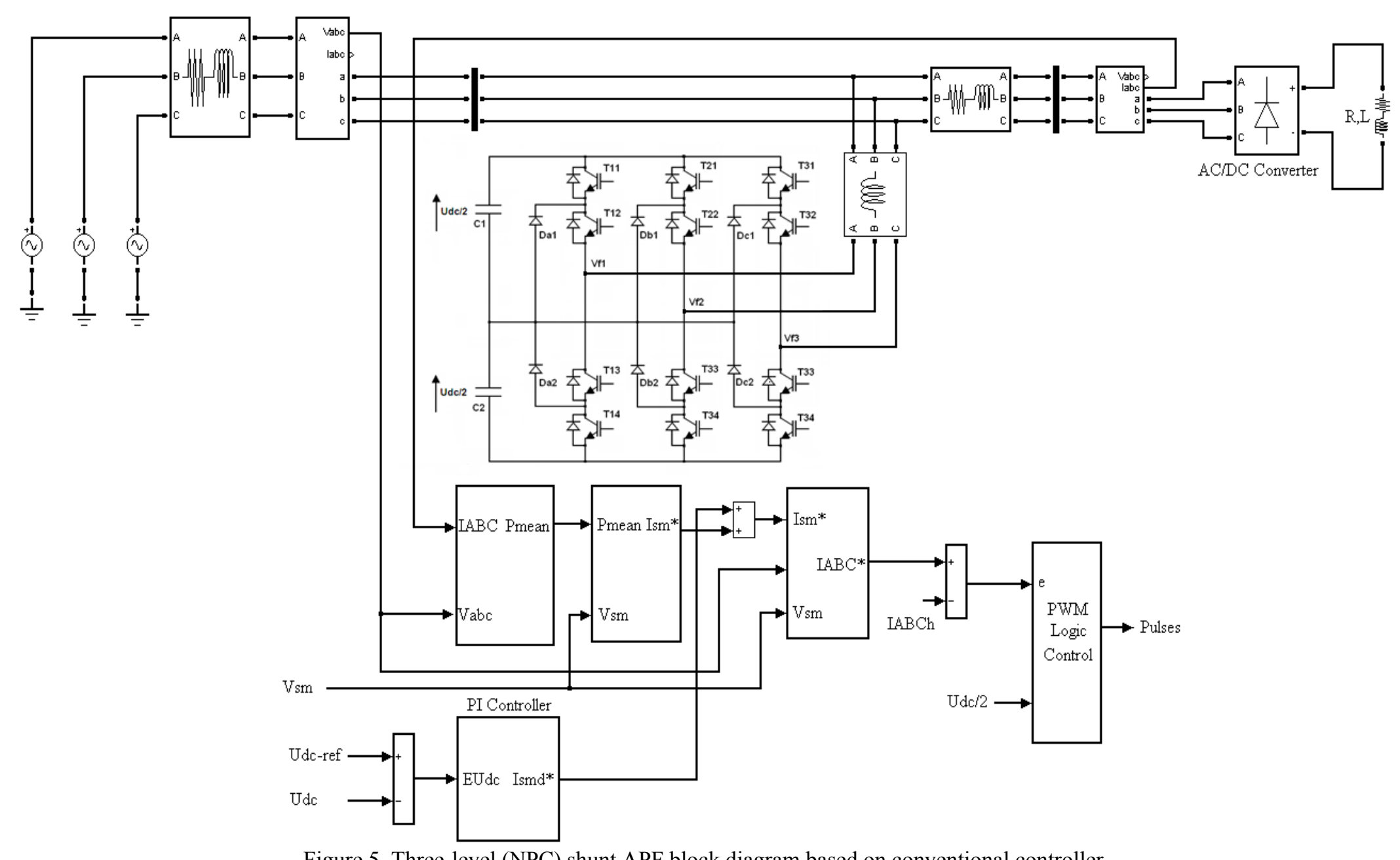

Figure 5. Three-level (NPC) shunt APF block diagram based on conventional controller 


\section{B. Ann's current controller}

Artificial Neural Networks have provided an alternative modeling approach for power system applications. It is essentially a cluster of suitably interconnected non-linear elements of very simple form that possess the ability of learning and adaptation. These networks are characterized by their topology, the way in which they communicate with their environment, the manner in which they are trained and their ability to process information. The MLPNNs is one of the most popular topologies in use today [16], the structure model of this topology is shown in Figure 6. It consists of input layer, output layer and hidden layer, each layer has many neurons; choosing appropriate number of neurons of the hidden layer and activation function and threshold value of neurons, and determining the weight of connections between neurons through learning and training, it can realize approximation of any non-linear object with small error [17].

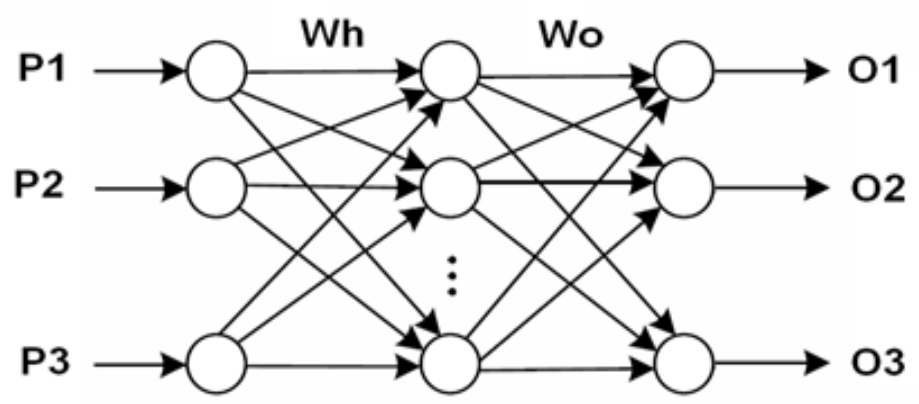

Figure 6. Three-layer neural network topology structure

Data flows into the network through the input layer, passes through the hidden layers and finally flows out of the network through the output layer. The network thus has a simple interpretation as a form of input-output model, with network weights as free parameters. The training cycle has two distinct paths, the first one is Forward propagation (it is the passing of inputs through the neural network structure to its output), the second one is the error backpropagation (it is the passing of the output error to the input in order to estimate the individual contribution of each weight in the network to the final output error) [18]. The weights are then modified so as to reduce the output error. To train the neural network current controller, the Quasi-Newton Levenberg-Marquardt Training algorithm is used, it is efficient, easy to implement and is not time consuming.

Computations of the algorithm proceed as follows:

1. Initialize the interconnection weights and the biases of the nodes randomly,

2. Calculate the hidden layer outputs as:

$$
x_{j}^{h}=f\left(\sum_{i=1}^{n i}\left(x_{i} w_{i, j}^{h}\right)+b_{j}^{h} w_{n i+1, j}^{h}\right)
$$

Where $x_{j}^{h}$ is the output of the hidden node $j, x_{i}$ is the i'th input, $w_{i, j}^{h}$ is the weight connecting input node $i$ with hidden node $j, b_{j}^{h}$ is the input bias to hidden node $j$ (normally $\left.b_{j}^{h}=1\right), w_{n i+1, j}^{h}$ is the weight connecting the bias to the hidden node $j, n i$ is the number of input nodes, and $f$ is sigmoid function defined as: 


$$
f(x)=\frac{1}{1+e^{-x}}
$$

3. Calculate the output layer outputs as:

$$
x_{k}^{0}=f\left(\sum_{j=1}^{n k}\left(x_{j}^{h} w_{j, k}^{0}\right)+b_{k}^{0} w_{n k+1, k}^{0}\right)
$$

Where $x_{k}^{0}$ is the output of the output node $k, w_{j, k}^{0}$ is the weight connecting the hidden node $j$ with output node $k, b_{k}^{0}$ is the input bias to the output node $\mathrm{k}$ (normally $b_{k}^{0}=1$ ), $w_{n k+1, k}^{0}$ is the weight connecting the bias to the output node $k$ and $n k$ is the number of hidden nodes.

4. Calculate $\delta_{k}^{0}$ of each of the output nodes as:

$$
\delta_{k}^{0}=x_{k}^{0}\left(1-x_{0}^{k}\right)\left(x_{k}^{T}-x_{0}^{k}\right)
$$

Where $\delta_{k}^{0}$, is the error (target-output) at the output of the neuron multiplied by the derivative of $f(x), x_{k}^{T}$ is the target output (desired output) of the output node $k$.

5. Calculate $\delta_{j}^{h}$ each of the hidden nodes as follows:

$$
\delta_{j}^{h}=x_{j}^{h}\left(1-x_{j}^{h}\right) \sum_{k=1}^{n o} \delta_{k}^{0} w_{j, k}^{0}
$$

Where $\delta_{j}^{h}$ the derivative of is $f(x)$ multiplied by the summation of the weights multiplied by the output delta,

6. Adapt the weights of the output layer as:

$$
w_{j, k}^{0}(t+1)=w_{j, k}^{0}(t)+\eta \delta_{k}^{0} x_{j}^{h}+\alpha \Delta w_{j, k}^{0}(t)
$$

Where $0<\eta<1$ is the learning constant, $0<\alpha<1$ is the momentum constant and,

$$
\Delta w_{j, k}^{0}(t)=w_{j, k}^{0}(t)-w_{j, k}^{0}(t-1)
$$

7. Adapt the weights of the hidden layer as:

$$
w_{i, j}^{h}(t+1)=w_{i, j}^{h}(t)+\eta \delta_{j}^{h} x_{i}+\alpha \Delta w_{i, j}^{h}(t)
$$

Where,

$$
\Delta w_{i, j}^{h}(t)=w_{i, j}^{h}(t)-w_{i, j}^{h}(t-1)
$$


8. Repeat steps 1 to 7 until the error e is less than a prescribed small value $\varepsilon$.

$$
e=\sum_{k=1}^{n o}\left(x_{k}^{T}-x_{k}^{0}\right)^{2}
$$

The flow chart for training ANN controller is given by Figure (7).

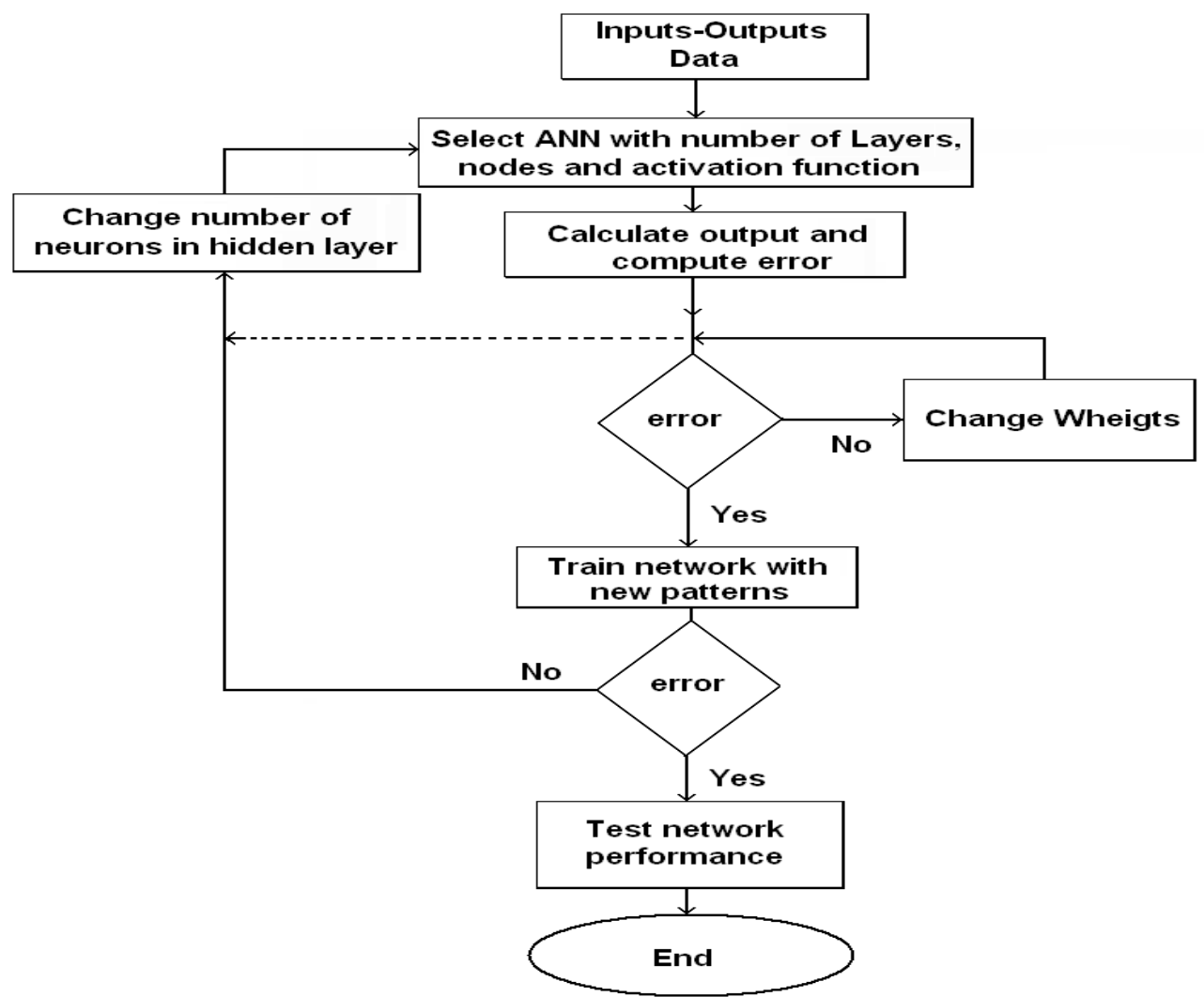

Figure 7. Flow chart for training Ann's controller

For the three-level (NPC) inverter, the proposed Ann's current controller is shown in Figure 8. The input pattern is the error values (Eca, Ecb and Ecc) between the measured filter currents (ifa, ifb and ifc) and the compensating reference currents (ifa*, ifb* and ifc*) [9], [10] and [14]. Whereas the outputs values are the switching states T11, T12, T21, T22, T31 and T32. The hidden layer contains 12 neurons with a sigmoid activation function and the output layer contains six neurons with a linear activation function. The network was trained with 10000 training examples using Levenberg-Marquardt back propagation algorithm. 


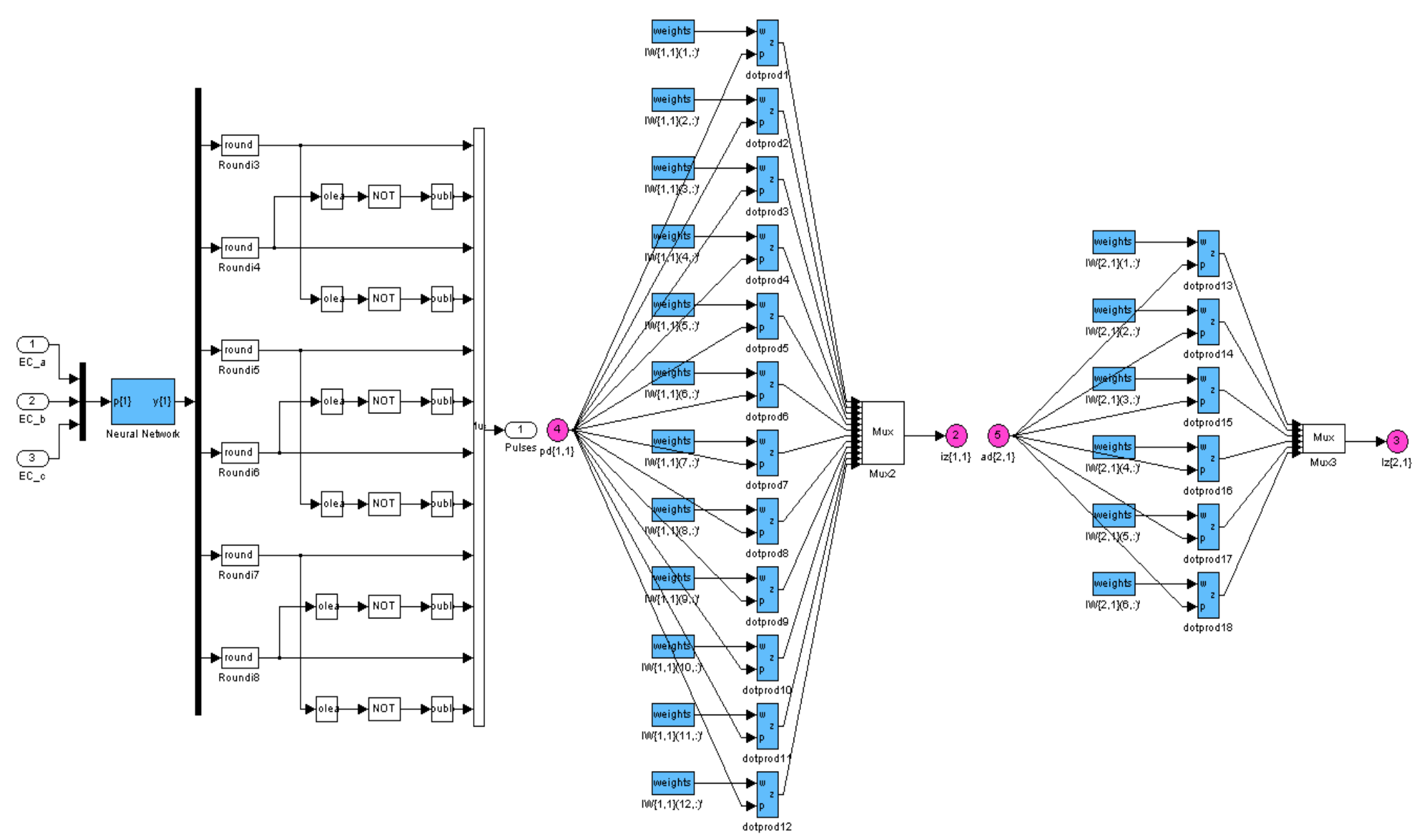

Figure 8. Ann's current controller 
Three-phase Three-level (NPC) Shunt Active Power Filter Performances

The bloc diagram of the three-level (NPC) shunt APF based on Ann's current controller is shown in Figure (9).

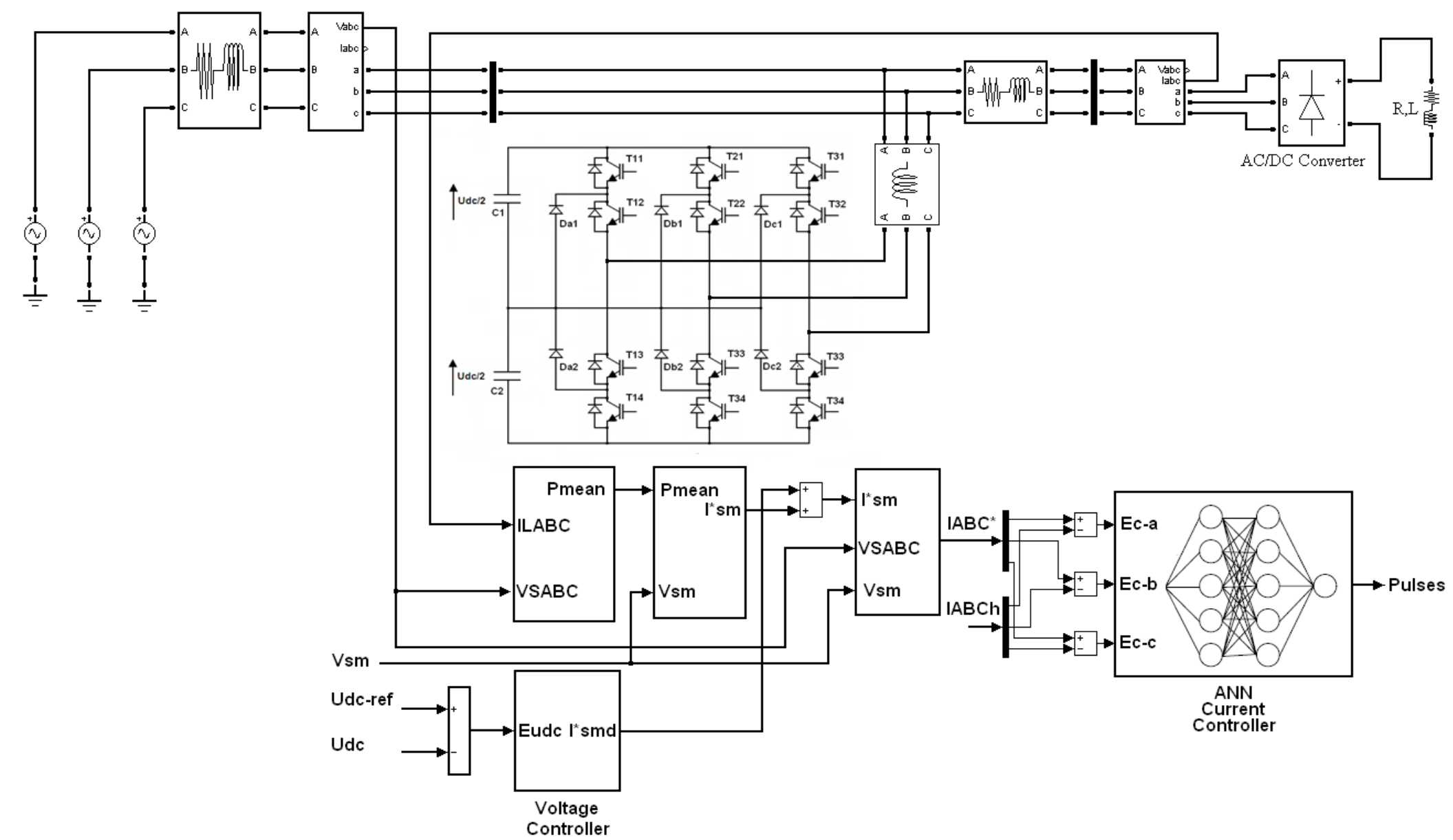

Figure 9. Three-level (NPC) shunt APF block diagram based on Ann's current controller 
Figure (10) shows the Matlab-Simulink simulation block diagram of the proposed Shunt APF based on artificial neural network current controller.

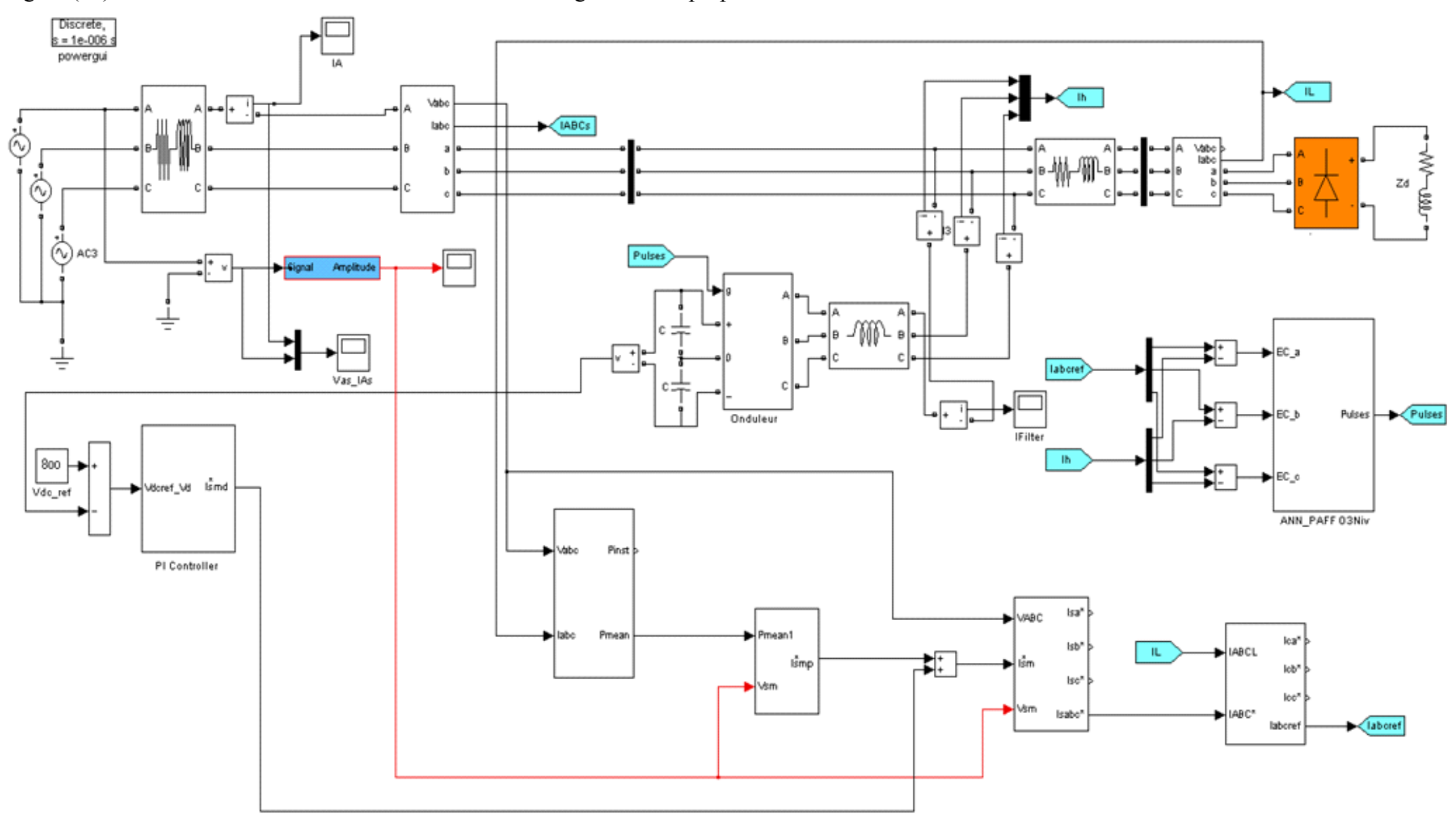

Figure 10. Three-level (NPC) shunt APF simulation model based on Ann's current controller 


\section{Simulation results and discussion}

The simulation results are provided to verify the performance and effectiveness the threelevel (NPC) shunt active power using PWM and Ann's current controllers. The active filter is composed mainly of the three-phase source, three-level (NPC) inverter, nonlinear load (Rectifier \& R,L). The parameters of the simulation are: $\mathrm{Lf}=3 \mathrm{mH}, \mathrm{C} 1=\mathrm{C} 2=3000 \mu \mathrm{F}, \mathrm{Vs}=$ $220 \mathrm{~V} / 50 \mathrm{~Hz}$ and Udc-ref $=800 \mathrm{~V}$.

\section{A. Simulation results using conventional controller}

Figure (11) shows the simulated waveforms of the source current before compensation. The corresponding harmonic spectrum is shown in Figure 12. The source current and injected current before and after APF application are shown in Figures 13 and 14, respectively. The DC voltage is presented in Figure 15. The waveforms of source voltage and source current after compensation are simultaneously shown in Figure 16. The harmonic spectrum of the source current after compensation is shown in Figure 17.

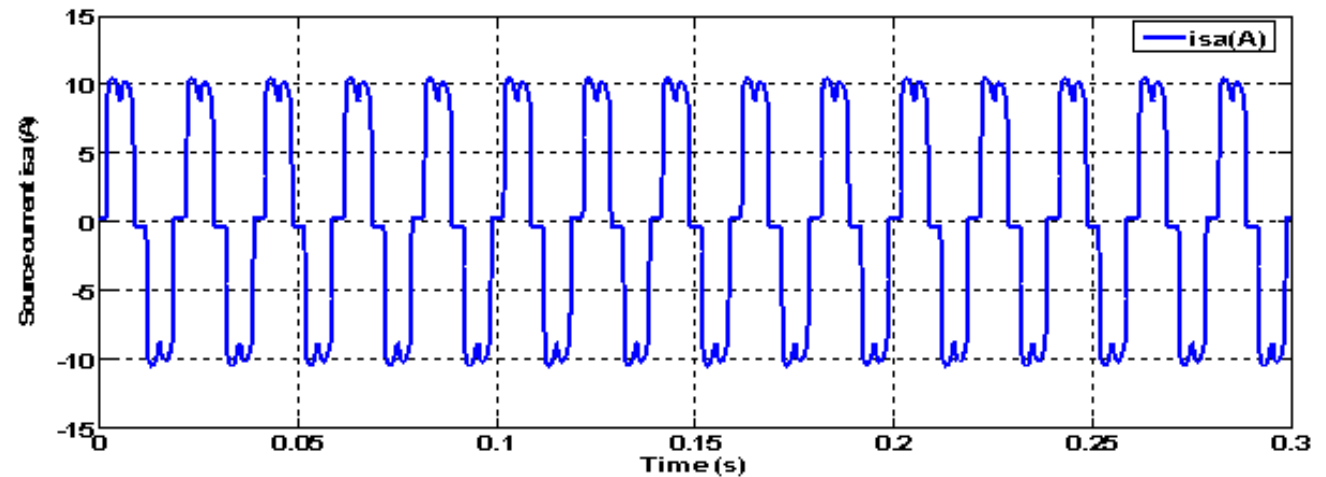

Figure 11. Source current without Shunt APF

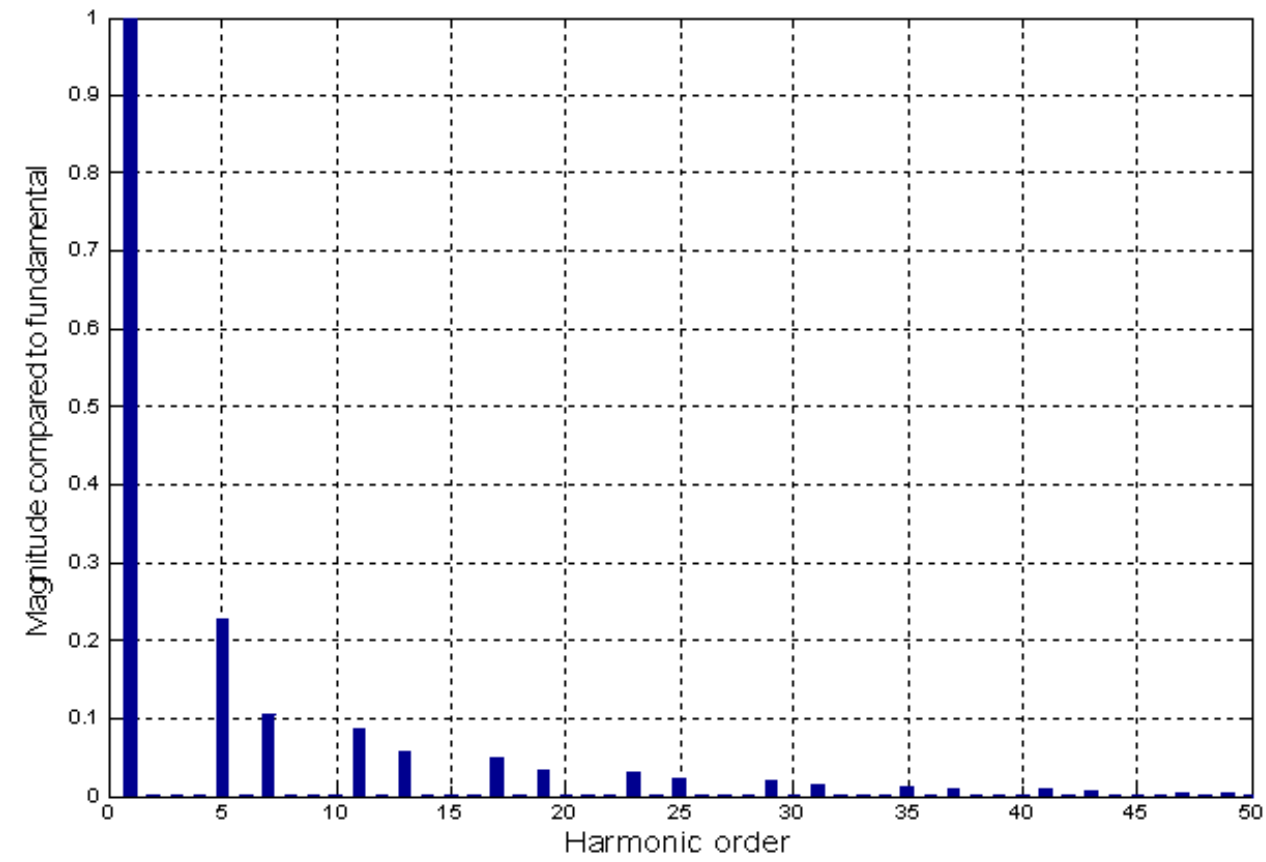

Figure 12. Source current spectrum without Shunt APF: THDi $(\%)=28.16 \%$ 


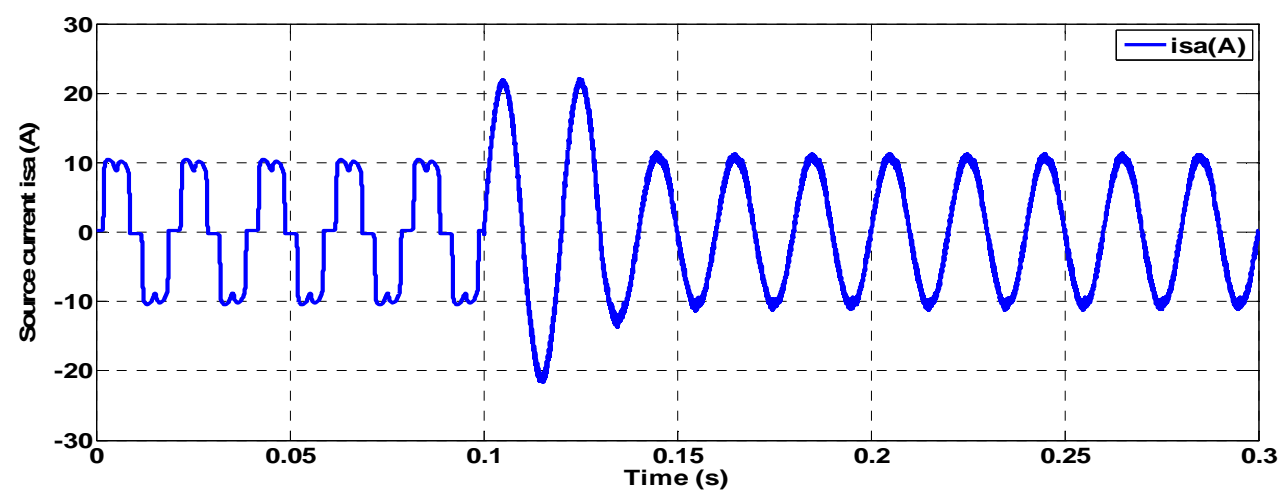

Figure 13. Source current isa (A) before and after compensation using conventional controller

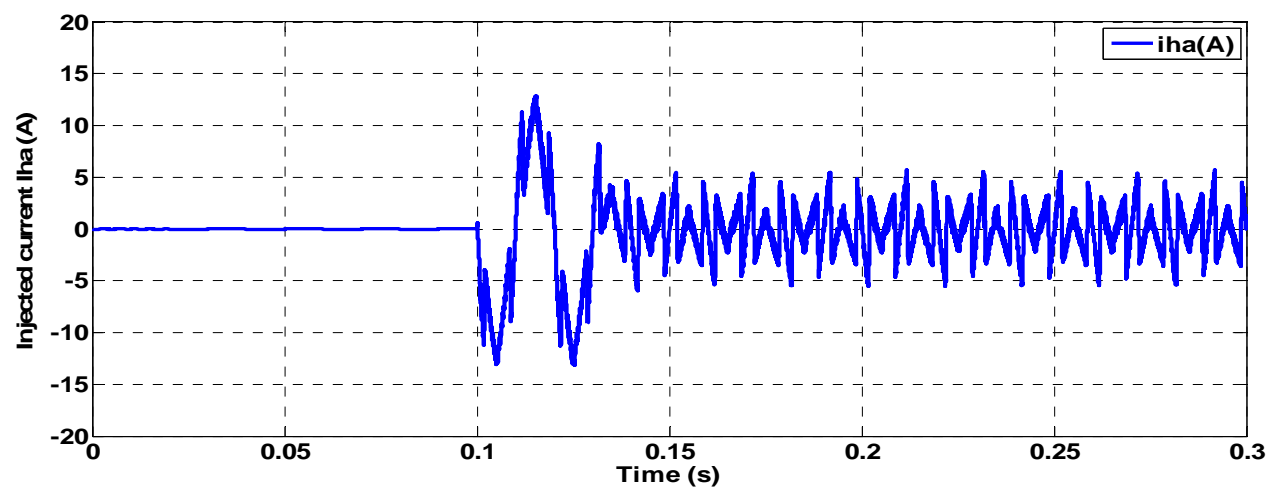

Figure 14. Injected current iha (A)

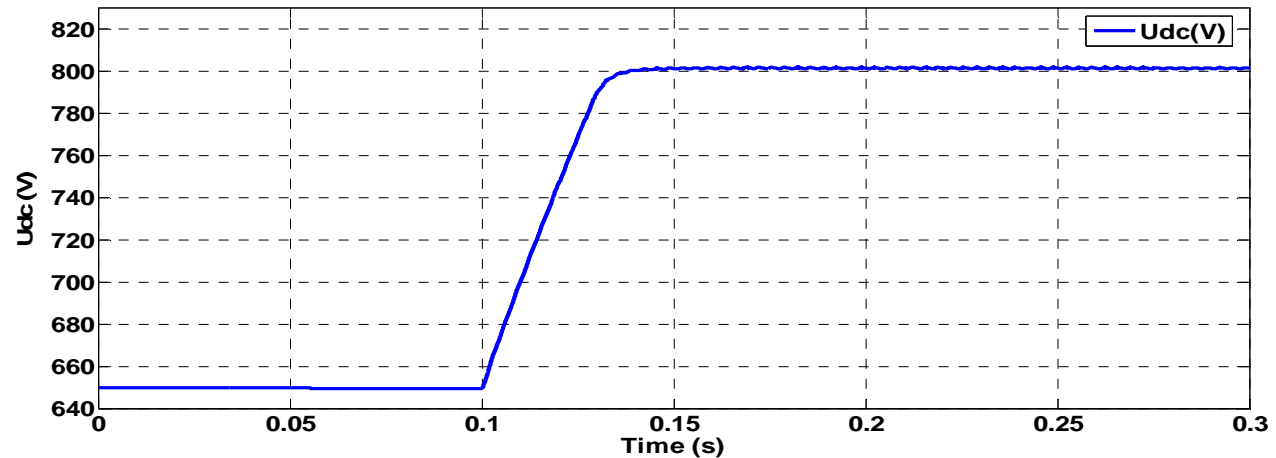

Figure 15. DC side capacitor voltages Udc (V) 


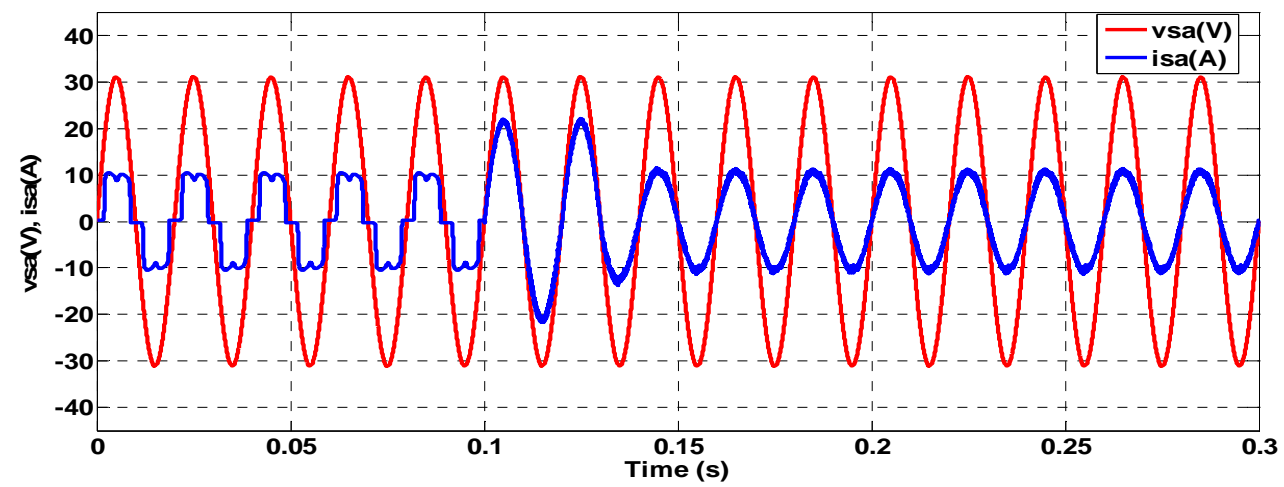

Figure 16. Current source isa (A) and voltage source vsa (V) before and after compensation

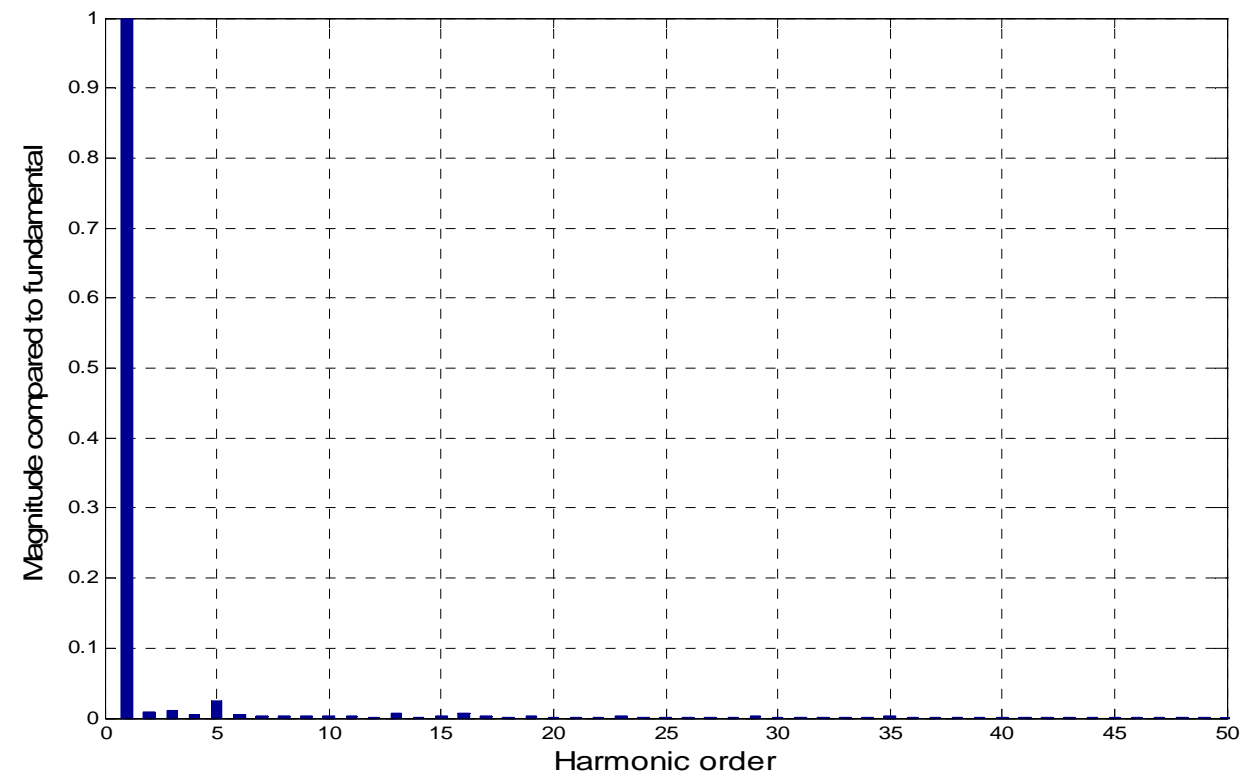

Figure 17. Source current spectrum with Shunt APF: THDi (\%) $=4.32 \%$

B. Simulation results using conventional controller with sudden step change in load

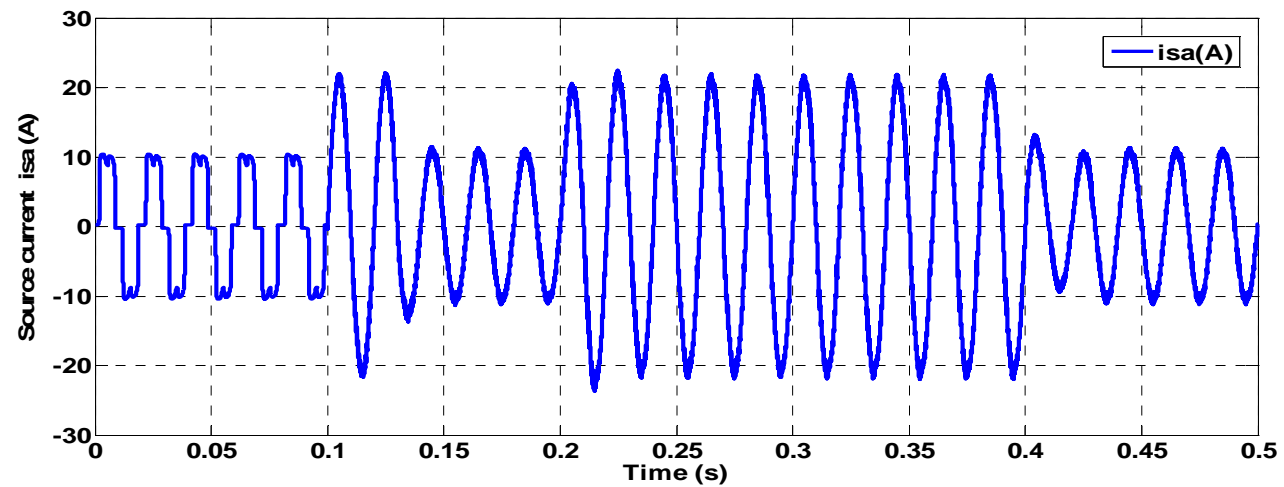

Figure 18. Source current isa (A) with step change in load (between $\mathrm{t} 1=0.2 \mathrm{~s}$ and $\mathrm{t} 2=0.4 \mathrm{~s}$ ) 
To evaluate dynamic responses and test robustness of the proposed shunt active filter a step change in load is introduced between $t 1=0.2 \mathrm{sec}$ and $\mathrm{t} 2=0.4 \mathrm{sec}$. Figures 18 and 19 show the respective waveforms of the source current and injected current before and after compensation. The dc side capacitor voltage is shown in Figure 20. The current and the voltage source waveforms before and after compensation are simultaneously presented in Figure 21.

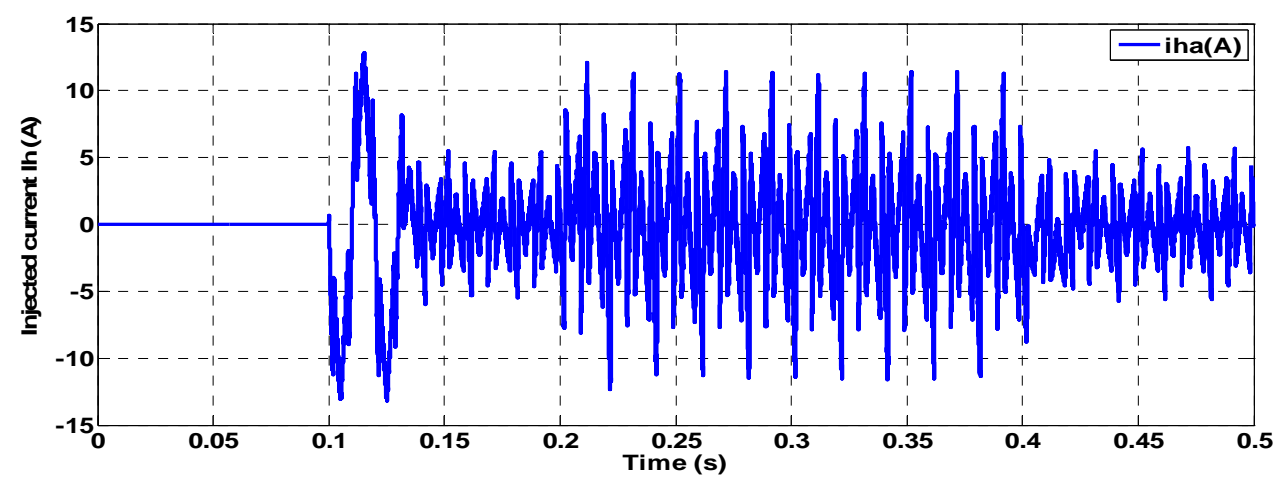

Figure 19. Injected current iha (A) with step change in load (between $t 1=0.2 \mathrm{~s}$ and $\mathrm{t} 2=0.4 \mathrm{~s}$ )

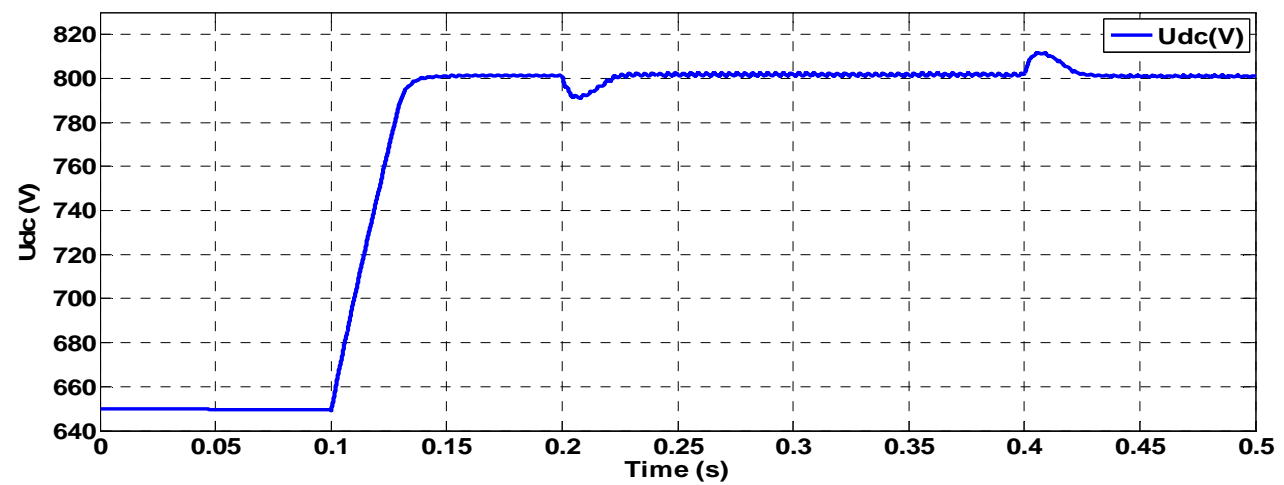

Figure 20. DC side capacitor voltage with step change in load (between $\mathrm{t} 1=0.2 \mathrm{~s}$ and $\mathrm{t} 2=0.4 \mathrm{~s}$ )

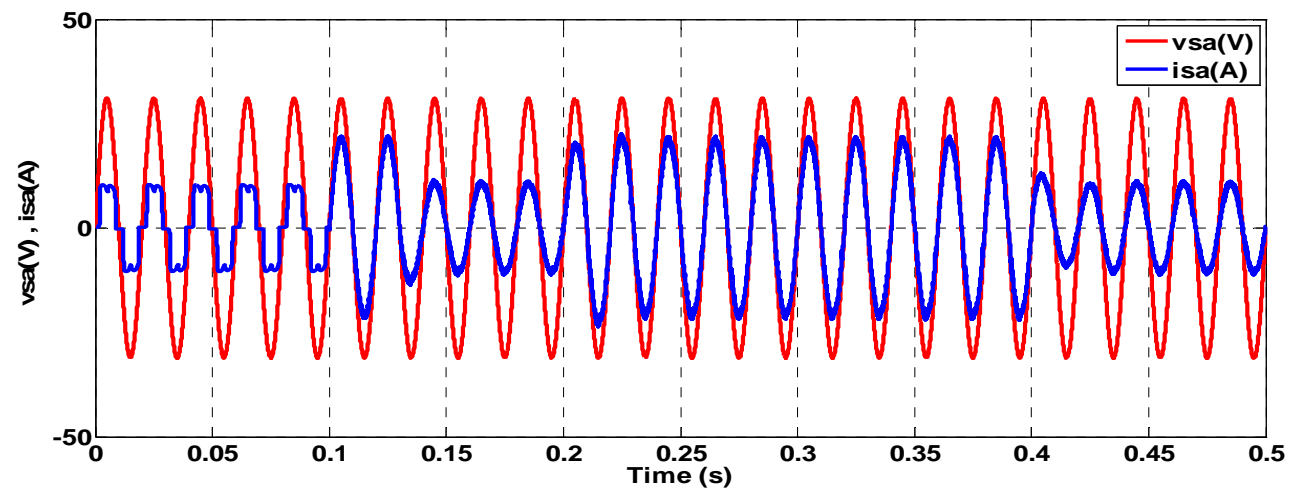

Figure 21. Current and voltage source before and after compensation with step change in load (between $\mathrm{t} 1=0.2 \mathrm{~s}$ and $\mathrm{t} 2=0.4 \mathrm{~s}$ ) 


\section{Simulation results using Ann's currant controller}

The source current and injected current before and after APF application using Ann's controller are respectively shown in Figures 22 and 23. The output DC capacitor voltage is presented in Figure 24. The waveforms of source voltage with source current after compensation are simultaneously shown in Figure 25. The harmonic spectrum of the source current after compensation is shown in Figure 26.

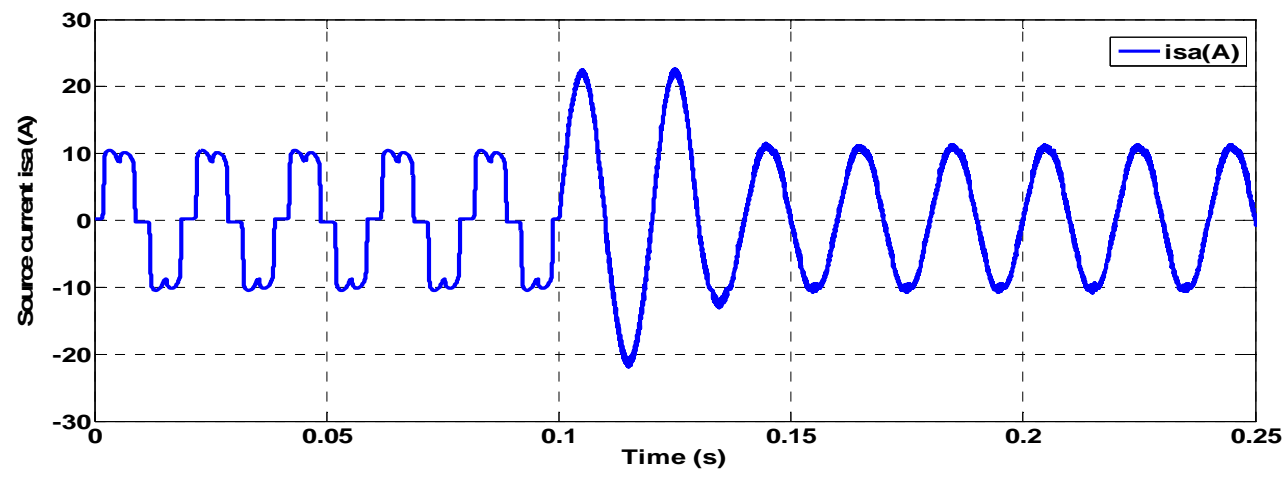

Figure 22. Source current isa (A) before and after compensation using Ann's controller

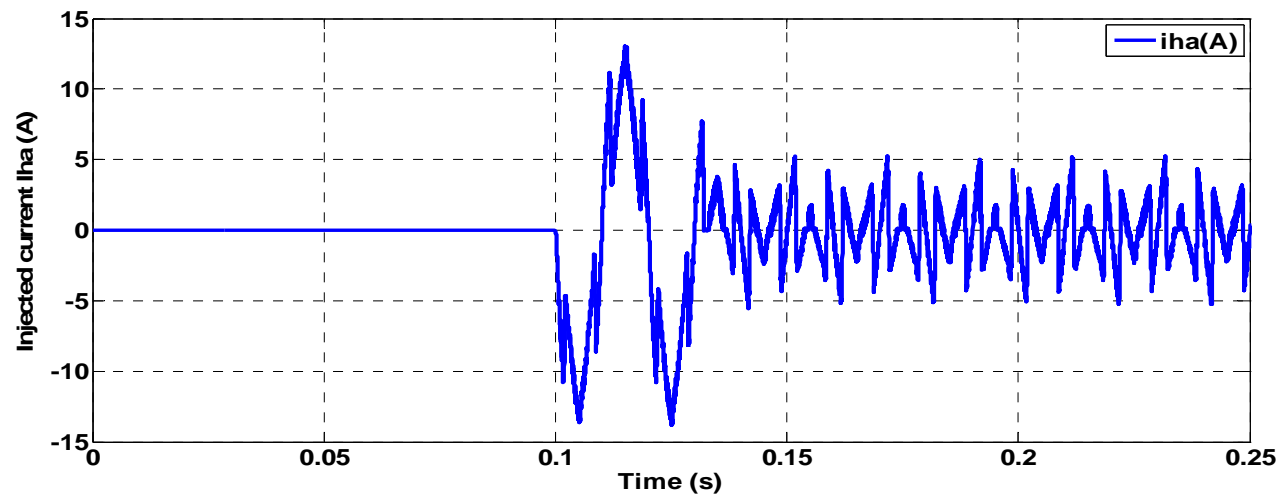

Figure 23. Injected current iha (A)

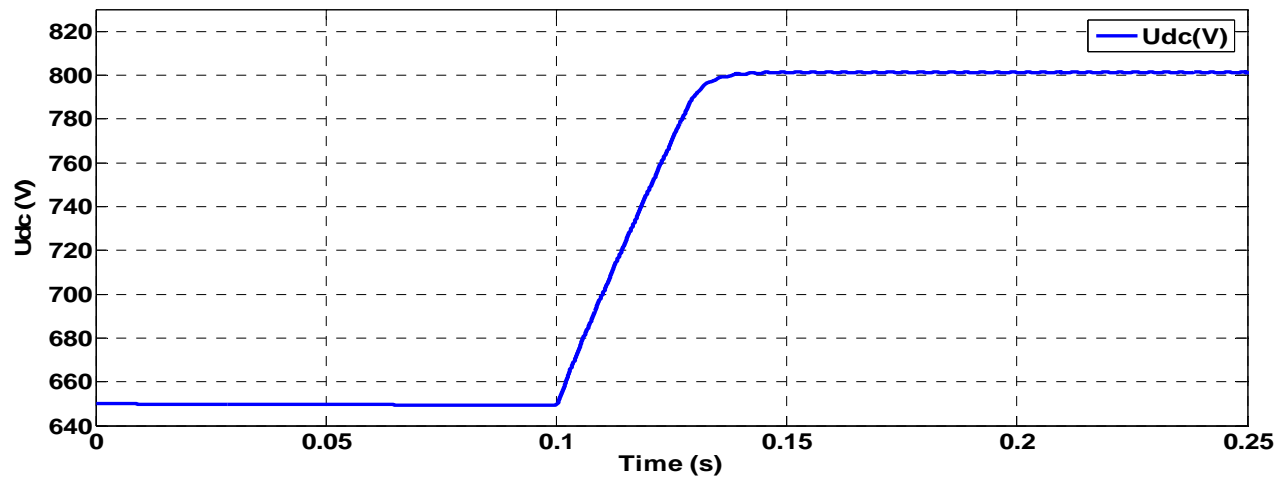

Figure 24. DC side capacitor voltages Udc (V) 


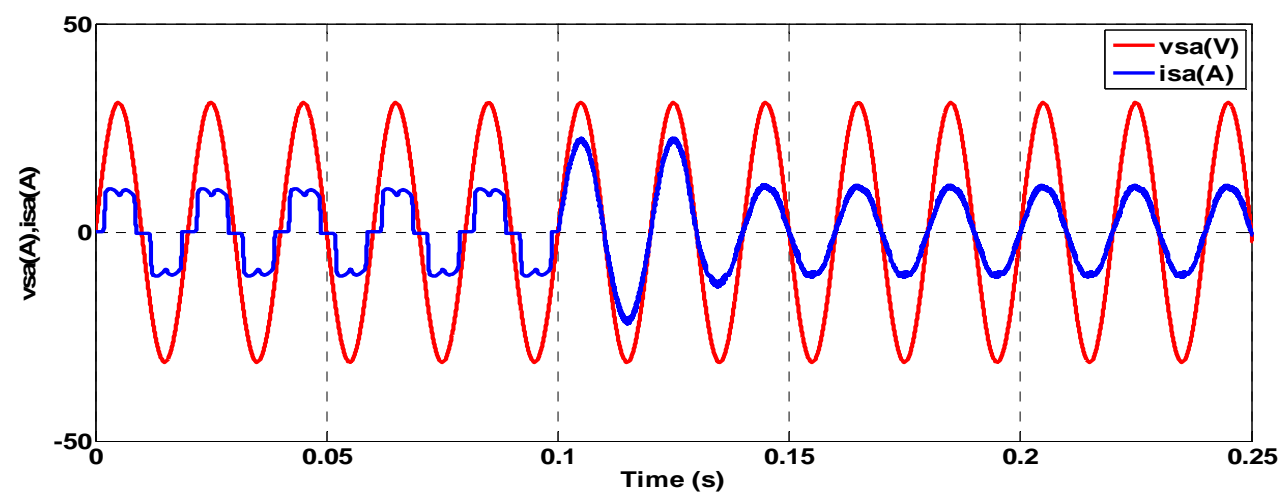

Figure 25. Current source isa (A) and voltage source vsa (V) before and after compensation

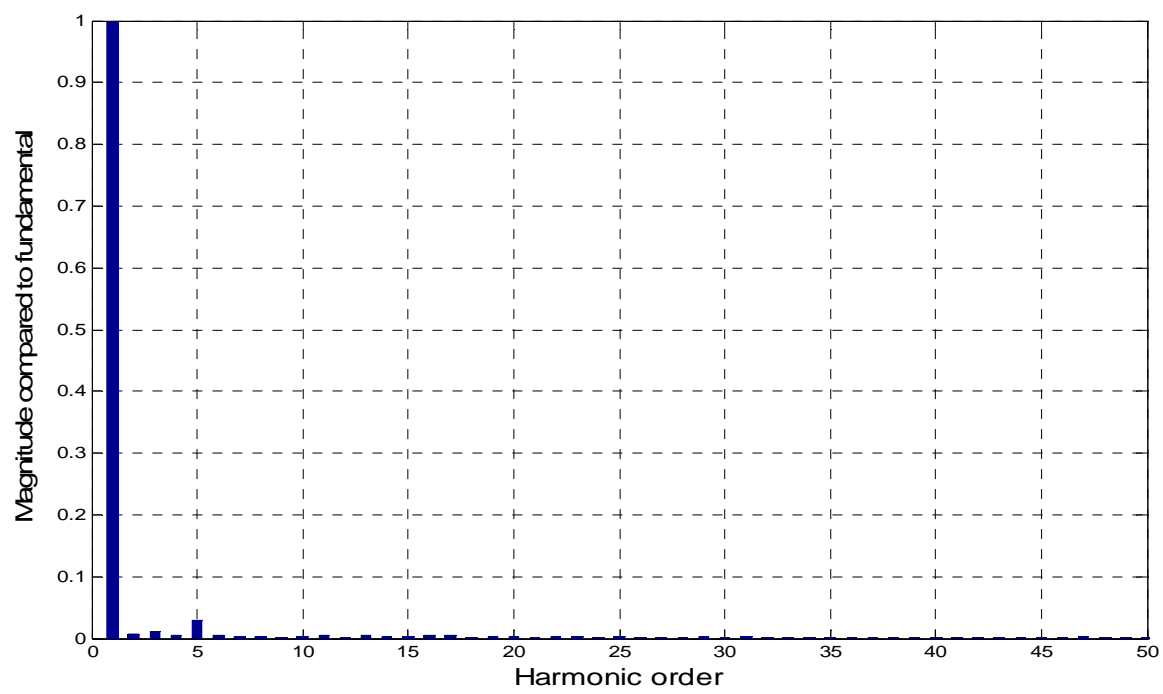

Figure 26. Source current spectrum with APF using Ann's current controller:

$$
\text { THDi }(\%)=3.96 \%
$$

Through visualization (Figs. 13, 18, and 22), we are able to conclude that the operation of the proposed three-level shunt APF based on conventional and Ann's current controllers is successful. Before the application of shunt APF, the source current is equal to non-linear load current; highly distorted and rich in harmonic. After compensation, the THDi is considerably reduced from $28.16 \%$ to $3.96 \%$ for Ann's controller and to $4.32 \%$ for conventional controller. The dc voltage is maintained at a constant value which is equal to the reference value Udc-ref $=800 \mathrm{~V}$ by using PI voltage controller. Figures 20 and 21 illustrate the dynamic response of the proposed shunt APF. It is observed that the dc voltage pass through a transitional period of $0.06 \mathrm{~s}$ before stabilization and reaches its reference Udc-ref $=800 \mathrm{~V}$ with moderate peak voltage approximately equal to $7 \mathrm{~V}$ when a step change in load current is introduced between $\mathrm{t} 1=0.2 \mathrm{~s}$ and $\mathrm{t} 2=0.4 \mathrm{~s}$. Figures 16, 21, and 25 demonstrate that after active filter application, the current source is sinusoidal and in phase with the voltage source. The performance of the three-level shunt active filter based on Ann's controller in terms of harmonics elimination and reactive power compensation is very satisfactory and better than conventional current controller. The THDi values obtained with the two controllers respect the IEEE standard Norms of THDi $\leq 5 \%$. 


\section{Conclusion}

In the present paper, a three-phase three-level (NPC) shunt active power filter with neutralpoint diode clamped inverter based on PWM and Ann's current controllers are presented. Use of the filter is aimed at achieving the elimination of harmonics introduced by nonlinear loads. Several simulations with nonlinear loads composed by AC/DC converter with R,L loads under different conditions are performed. The simulation results show the robustness and effectiveness of the proposed Ann's controller in terms of eliminating harmonics compared to conventional currant controller. The THDi is significantly reduced from $28.16 \%$ to $4.32 \%$ using conventional controller and to 3.96\% using Ann's controller in conformity with the IEEE standard norms. The control strategy based on synchronous current detection method permits a good extraction of reference currents compensation. The PI Controller ensures that the dc voltage across capacitor is maintained constant and equal to reference vale (Udc-ref $=800 \mathrm{~V}$ ). The steady state of the source current is obtained after $0.03 \mathrm{sec}$ in the two cases. The current source after compensation for the two proposed control scheme is sinusoidal and in phase with the line voltage source; the power factor is nearly equal to unity. Hence, the proposed Ann's current controller is excellent candidates to control shunt active filters based on multilevel inverter topology toward eliminating the harmonic currents and improving the power factor compared to conventional current controller.

\section{References}

[1] N. Gupta, S. P. Singh, and S. P. Dubey, "Neural network based shunt active filter for harmonic and reactive power compensation under non-ideal mains voltage", IEEE, pp. $370-375,2010$.

[2] J. Wang, "Simulation of three-phase three-wire shunt active power filter", International Journal of Sciences and techniques of automatic Control \& Computer engineering, Vol. 3, No 1 , pp. 942-955, 2009.

[3] R-H. Herrera, P. Salemeron, H. Kim, "Instantaneous Reactive Power Theory Applied to Active Power Filter Compensation: Different Approaches, Assessment, and Experimental Results”, IEEE, Trans. on Industrial Electronics, pp. 184-196, 2008.

[4] S. Bhattachrya, D. Divan, "Synchronous frame based controller implementation for a hybrid series active filter systems", IEEE, pp. 2531-2537, 1995.

[5] A. Chandra, B. Singh, K. Al-Haddad, "An improved control algorithm of shunt active filter for voltage regulation, harmonic elimination, power factor correction, and balancing nonlinear loads", IEEE Tran. on Power Electr, pp. 495-503, 2000.

[6] O. Vodyakho, T. Kim, S. kwak, "Comparison of the space vector current controls for shunt active power filters", IEEE, pp. 612-617, 2008.

[7] O. Vodyakho, D. Hackstein, A. Steimel, T. Kim, "Novel direct current-space vector control for shunt active power filters based on three-level inverters", IEEE, pp. 1868 1873, 2008.

[8] B. Lin, C-H Huang, T-Y. Yang and Y-C. Lee, "Analysis and Implementation of Shunt Active Power Filter with Three-Level PWM Scheme", IEEE, pp. 1580-1885, 2003.

[9] A. Zouidi, F. Fnaiech, K. Al-Haddad, "Neural Network three-phase three-wire shunt active filter", IEEE, pp. 5-10, 2006.

[10] A. Zouidi, F. Fnaiech, K. Al-Haddad, "Neural network controlled three-phase three-wire shunt active power filter", IEEE, ISIE, 2006.

[11] E.E. El-Kholy, A. El-Hefnawy, H.M Mahrous, "Three-phase active power based on current controlled voltage source inverter", Elsevier, Electric power and Energy Systems 28, pp. 537-547, 2006.

[12] S. Chennai, M-T. Benchouia, "Intelligent controllers for shunt active filter to compensate current harmonics based on SRF and SCR control strategies", International journal on Electrical Engineering and Informatics, IJEEI, Vol.3, No.3, pp. 372-393, 2011.

[13] Y. Wan, J. Jiang, "The study of FPGA-based three-level SVM NPC inverter", IEEE, pp. 1470-1474, 2009. 
[14] S. Chennai and M-T. Benchouia, "Shunt active power filter performances based on threelevel (NPC) inverter to compensate current harmonics using intelligent controller", $8^{\text {th }}$ Electrical Engineering Conference CGE'08, 16 and 17 April 2013, Algeria (2013).

[15] S. Chennai and M-T. Benchouia, "Simplified Control Scheme of Unified Power Quality Conditioner based on Three-phase Three-level (NPC) inverter to Mitigate Current Source Harmonics and Compensate All Voltage Disturbances", Journal of Electrical Engineering \& Technology, JEET (KIEE), Vol.8, No.3, pp.544-558, May 2013.

[16] G. Liu, S. Su, P. Peng, "Intelligent Control and Application of All-function Active Power Filter", IEEE, International Conference on Intelligent Computation Technology and Automation, pp. 1078-1081, 2008.

[17] V-S. Kumar, D. Kavitha, K. Kalaiselvi and P-S. Kannan, "Harmonic Mitigation and Power Factor Improvement using Fuzzy Logic and Neural Network Controlled Active Power Filter", Journal of Electrical Engineering \& Technology, JEET (KIEE) , Vol.3, No.3, pp. 520-527, 2008.

[18] Y-H. Jiang, Y-W. Chen, "Neural network control techniques of hybrid active power filter", International Conference on artificial Intelligence and computational intelligence, pp. 26-30, 2009.

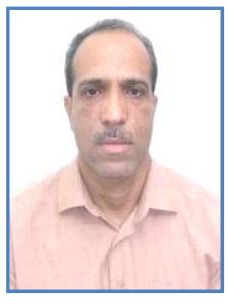

Chennai Salim was born in Biskra, Algeria, on February 03, 1969. He obtained his engineering degree in Electrotechnics from Biskra University in 1992. He was recruited in 1993 as senior engineer in power electronics in Birine Nuclear Research Center, Algeria. Since 2000, he has been working as researcher in the Electrical Engineering Department. He obtained his M.Sc degree in electrical engineering in 2009 from Media University, Algeria and his Ph.D. degree in Electrical Engineering from Biskra University in 2013, Algeria. His research interests are electrical drives, power electronics, energy quality, power systems, and intelligent control.

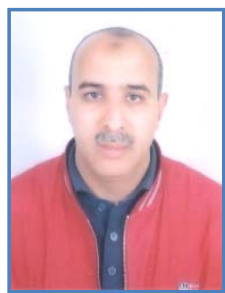

Benchouia Mohamed Toufik was born in Biskra, Algeria. He received his Engineer degree in Electrotechnics and Magister degree in electrical engineering from Biskra University in 1991 and 1998 respectively. He received his Ph.D. in electrical engineering from Biskra University in 2006. Since 2001 he has held a teaching and research position in the Department of Electrical Engineering of Biskra University, Algeria. His research interests are in electrical drives, power electronics and power systems. 